\title{
Corporate Disruption: The Law and Design of Organizations in the Twenty-First Century
}

\author{
William Callison ${ }^{1} \cdot$ Mark Fenwick $^{2} \cdot$ Joseph A. McCahery ${ }^{3} \cdot$ Erik P. M. Vermeulen $^{4}$
}

Published online: 22 October 2018

(c) The Author(s) 2018

\begin{abstract}
This paper explores the issue of 're-making' corporate law through the prism of the United Nations' recent efforts at reducing legal obstacles experienced by micro-, small- and medium-sized enterprises in starting and scaling a business. In order to be fully successful, this paper suggests that the UN should go back to business fundamentals and should attempt to build from the ground up based on the real world needs of entrepreneurs, rather than work off already existing corporate legal systems. In this way, it is possible to engage in a more imaginative form of regulatory design in which a clear, open and preferential legal framework for stimulating innovation and business creation can be developed.
\end{abstract}

Keywords Company · Corporate governance · Corporation · Formal economy · Freedom of contract · Hybrid business forms · Informal economy · Micro-finance · Organization · Theory of the firm · Un-corporation · Ventures

Joseph A. McCahery

J.A.McCahery@uvt.nl

William Callison

William.callison@FaegreBD.com

Mark Fenwick

Mdf0911@gmail.com

Erik P. M. Vermeulen

E.P.M.Vermeulen@uvt.nl

1 Faegre Baker Daniels, Denver, USA

2 Kyushu University, Fukuoka, Japan

3 Tilburg University, Tilburg, The Netherlands

4 Tilburg University/Philips Lighting, Tilburg, The Netherlands 


\section{Introduction}

In economies characterized by static, closed markets, the formal hierarchies of modern corporate law functioned as an important and effective site of innovation and business creation that drove economic development. However, in today's hypercompetitive, global markets such structures are proving far less durable. Many policy makers and other commentators have identified the need for new organizational forms appropriate to the new economy, particularly in the context of smaller enterprises in the formative and early stages of the corporate life cycle. There is a sense that existing corporate law forms are overly bureaucratized and out of touch with the contemporary business needs of micro-, small- and medium-sized enterprises.

Against this background, some countries have embraced the idea of 'un-corporating' corporate law via the introduction of more open, flexible and 'flat' organizational forms. Even in those jurisdictions where such reforms have not been adopted, there is greater recognition of the social reality that everyone is more entrepreneurial and that providing a vehicle to facilitate this entrepreneurialism is a pressing issue for all levels of government. In the context of the 'new economy' it seems that the most successful firms are less likely to take the form of vast behemoths with thousands of employees. Rather, the economy of the future seems likely to be characterized by a plurality of organizational models in which business is conducted in a framework of contractual transactions, sole-proprietorships, or platform-type organizational structures. ${ }^{1}$ Obvious examples of this trend would be Uber and Airbnb.

This paper explores the issue of 're-making' corporate law through the prism of the United Nations Commission on International Trade Law's (UNCITRAL) recent efforts at reducing legal obstacles experienced by micro-, small- and medium-sized enterprises (MSMEs). ${ }^{2}$ In particular, we explore an UNCITRAL project developing a simplified organizational form that aims to bring micro- and small-sized business enterprises into the formal economy, particularly in the context of emerging markets. But the implications of this project go beyond the issue of offering street vendors the opportunity and means to formalize their business. The new legal form has the potential to offer anyone wishing to start and scale a business with the legal means to do so. In this way, a simplified organizational form can contribute to a strengthening of the local economy and startup community, more generally, and-in a best case-provide an opportunity for smaller businesses to scale into successful national, and possibly global, enterprises.

In establishing an open and flexible organizational form that can perform these functions, it is crucially important to think about how we approach regulatory design in a corporate context. In particular, in developing a new organizational form of this kind we should not defer to what is already out there or seek to build on some compromise between existing legal approaches. Rather, it is preferable to start with a blank slate and build from the ground up. In particular, it is important to adopt an

\footnotetext{
1 Parker et al. (2016) and Fenwick et al. (2018).

2 Official Records of the General Assembly, Sixty-fourth Session, Supplement No. 17 (A/64/17), paras. pp 432-433.
} 
entrepreneur-oriented approach that prioritizes the real-world needs of entrepreneurs in selecting the most feasible legal solutions.

Such an approach represents the most effective means of encouraging entrepreneurs to enter the formal economy and to promote business creation, more generally. At least, this type of entrepreneur-led approach will be more effective than those approaches that simply aim at transplanting existing legal frameworks from other (more 'developed') jurisdictions or seek to build a harmonized model based on a compromise between laws existing elsewhere. In this respect, the United Nations is the ideal organization to engage in this task, because it is not bound by path-dependent legal traditions that constrain the imagination and perceived range of regulatory solutions.

Central to the argument developed here is the belief that in order to be fully successful, any organizational form needs to be flexible enough to accommodate the diversity of MSMEs. In particular, the regulatory framework needs to facilitate the 'flatter', flexible and more informal business practices associated with smaller and organizationally dispersed enterprises. We label this type of approach 'un-corporating' corporate law.

This type of approach to business regulation involves an important break with the traditional way that we think about corporations. Broadly speaking the history of corporate law is the history of a hierarchical model of the internal organization of the firm. ${ }^{3}$ According to this perspective, power and authority flow 'downwards' from the legal (and moral) 'owners' of the corporation (the shareholders) to the board and then to the managers and (finally) to the employees. Conversely, accountability flows in the opposite direction. When combined with the idea of limited liability, this hierarchically structured organizational form (the corporation) created new and unprecedented commercial possibilities that drove the initial growth and global expansion of capitalism. ${ }^{4}$

These commercial possibilities were first recognized in the context of large companies. Gradually, however, the benefits for smaller businesses were also seen and many jurisdictions introduced the possibility of a corporate form with limited liability for smaller enterprises. Contemporary interest in a corporate form appropriate to MSMEs is a continuation of this trend to expand the reach of the corporation as a strategy for stimulating innovation and entrepreneurship.

Nevertheless, although corporate law has traditionally been predicated on such a hierarchical model of the corporation, this hierarchical frame has proven highly problematic, particularly in the context of a contemporary business environment where agility and speed have become so crucial to a firm's prospects of success. The hierarchical frame has resulted in a proliferation of rules aimed at informing and protecting those individuals 'higher' up the hierarchy, most obviously the investorshareholders. The result is a set of rules and requirements that may not always be appropriate for smaller enterprises. For example, does it make sense to require an MSME to disclose the minutes of a meeting when that 'meeting' consists of a brief conversation between the founders as they pass each other on the stairs?

\footnotetext{
${ }^{3}$ Williamson (1985).

${ }^{4}$ Fenwick et al. (2017).
} 
Overly formal requirements can either become a drain on firm resources or (more likely) they are simply ignored, creating potential regulatory problems in the future. In this context, the regulatory challenge then becomes how to offer the benefits of a simplified corporate form to MSMEs without weighing that enterprise down with unwieldy and unrealistic requirements that will stifle its capacity for scaling and growth. Compliance should represent an opportunity for growth and not an irritating burden.

In the following we suggest that the solution to this dilemma is to 'un-corporate', i.e., to adopt an organizational form that is flatter, open and less-heavily regulated. This idea of the 'un-corporation' was first introduced by Larry Ribstein in The Rise of the Uncorporation. ${ }^{5}$ Ribstein realized that something was wrong with the hierarchical frame, in the sense that regulation was creating significant problems for large, publicly listed firms. Against this background, entrepreneurs and regulators saw advantages in alternative forms of business organization.

Ribstein's observations have been borne out by the fact that the best performing companies today are increasingly taking a flatter, open and more inclusive approach to their internal organizational structures. Recognition of the benefits of a move away from hierarchical, closed and static organizational forms has important implications for regulators contemplating the creation of a simplified corporate form for MSMEs. In the following, we suggest that it is only by adopting an 'un-corporated' model or un-corporated organization that such business model can hope to succeed.

This paper first considers the background to UNCITRAL's interest in this question of a new organizational form for MSMEs (Sect. 2) and a brief history of the rise of the corporate form (Sect. 3). The various different strategies that can be taken in developing a regulatory framework for a simplified organizational form in emerging markets are then introduced (Sect. 4). In this context, the paper introduces the idea of an entrepreneur-led responsive regulatory approach that looks to satisfy the core needs of entrepreneurs. These needs are introduced (Sect. 5). Foremost amongst these needs is the need for any simplified organizational form to be flat, open and flexible enough to accommodate the diverse realities of doing business in the twenty-first century (Sect. 6).

\section{Background, Context, and Purpose}

At its forty-sixth session in 2013, the Commission of UNCITRAL requested that a working group should start work aimed at reducing the legal obstacles and barriers encountered by micro-, small- and medium-sized enterprises throughout their life cycle (i.e., starting a business, operating a business, restructuring a business and dissolving a business). The underlying idea was that the higher the barriers the more likely it is that MSMEs are forced to start and operate their businesses in the informal economy. It is widely acknowledged that the informal economy will have a large number of disadvantages, namely a lack of credit, a lack of protection in the event of non-payment, unsafe working conditions, etc.

5 Ribstein (2010). 
UNCITRAL's Commission agreed that consideration of the issues relating to the creation of an enabling legal environment for MSMEs should focus on legal questions surrounding the simplification of business incorporation and registration; a system for resolving disputes between borrowers and lenders; effective access to financial services; guidance on ensuring access to credit; and insolvency.

In addition to reducing barriers to MSMEs entering the formal economy and helping them to maximize their economic potential, work on the simplification of business incorporation and registration has the potential to have additional international effects. In particular, an internationally recognized form of business registration could help to facilitate cross-border trade for MSMEs operating in regional markets, since it would provide a recognizable basis for transactions and avoid problems that may arise because of a lack of international recognition of the business form of the enterprise.

In its deliberations, the Working Group consistently emphasized the importance of focusing on the needs of micro- and small-sized businesses in its consideration of the legal issues surrounding the simplification of incorporation and operation. In order to offer the advantages of limited liability, legal personality and freedom of contract to micro-businesses, and to develop a simple, low-cost approach, a 'thinksmall-first' approach was taken.

The fundamental principle guiding this task was to focus on the needs of the entrepreneur operating the MSME and to identify simple and workable solutions that satisfy those needs. Adopting this approach, the Working Group considered four related strategies for developing a workable legal form for MSMEs.

The first strategy involves harmonizing existing corporate laws around a core of uniform rules that deal with the formation, operation and regulation of an MSMEfriendly business form. If differences among corporate law systems prevent the 'harmonization' process from coming to fruition, the focus could be redirected to 'compromise law-making' which is characterized by the adoption of a legal framework that is familiar to the donor jurisdictions (as understood and appreciated by their lawmakers).

However, due to the fragmentation and the lack of a general concept on the part of the members of the Working Group, a third strategy, which we term 'linking', may be suggested as a best-case scenario. This strategy entails that the regulation of a new business form will be kept at a minimum (only comprising the most important topics, such as incorporation, registration, limited liability protection) while existing corporate law rules fill the remaining gaps. A 'linked', but nevertheless 'new', legal business form makes sense when one realizes that the overwhelming majority of business enterprises in the world are 'one-person' businesses. In the context of globalization and ever-closer economic integration, it is increasingly important to strengthen the economic position of such micro-enterprises.

Clearly, the benefits of the latter approach are that new rules and regulations do not attempt to reform existing corporate law legislation. The strategy avoids prolonged dogmatic and doctrinal debate. The end result is the coexistence of both regimes which simultaneously compete with and complement one another. A very 
successful example of this approach is the Sociedad por Acciones Simplificada in Colombia (C-SAS). ${ }^{6}$

While linking makes sense at a country level, the question is whether UNCITRAL should adopt this approach. In this context, perhaps 'responsive lawmaking' can provide an alternative and preferred approach. A UNCITRAL legislative guide or model law could build on the presumption that a legislative regime for a readymade business form should focus on the real world needs of the smallest business entities first.

Two basic principles could then guide deliberations on these issues. Firstly, it is important to remain focused on the real world needs of entrepreneurs operating MSMEs in emerging markets, and to maintain a focus on the issue of what the law can do in order to satisfy those needs. Satisfying the needs of the entrepreneur must always be the overriding consideration in any decision as to the appropriate legal rule and overall framework. Secondly, in designing a legal framework that facilitates entrepreneurs in their business activities and aims to integrate them in the formal economy, the law must satisfy their expectations, but it also needs to protect them against circumstances or events that they do not necessarily foresee. This second principle is not incompatible with an overriding emphasis on the needs of entrepreneurs, but involves acknowledging that entrepreneurs may not always be in the best position to foresee every possible negative eventuality and that protecting against such risks is an important aspect of regulatory design in this context.

In order to determine which of the above four approaches represents the best strategy, the history of corporate law will be briefly discussed, as learning the lessons from the historical experience of lawmaking in this field can provide important clues as to the best path forward.

\section{A History of Corporate Law}

When trade started to revive in the Middle Ages, after a long economic slowdown, mediaeval merchants needed a business organization form that could bring together scarce capital and adventurous entrepreneurs willing to undertake difficult and perilous overseas voyages. In response to the influence of the nobility and the clergy, the legal (Mercantile) systems began to acknowledge the commenda with its Jewish, Byzantine, and Muslim origins. The commenda, which evolved from a loan contract into a limited partnership-type business form, was intended to mobilize risk capital for short-term overseas commercial ventures. ${ }^{7}$ This limited partnership-type business form offered investors limited liability and anonymity, and thus made it possible for investors to pour money into lucrative ventures without risking being condemned for usury or violating prohibitions against engaging in trade. Because the investors could not be involved in the decision-making process, the limited liability feature

\footnotetext{
6 Reyes (2015a, b).

7 Berman (1983).
} 
was viewed to be efficient as it introduced the prospect of limiting the costs of monitoring and control of management and managerial misbehavior. The function of limited liability also increased liquidity, and promoted diversification, which reduced the level of risk overall. In fact, by having access to limited liability the investors only risked losing their initial investment, which furthered the emergence of risk capital. The commenda evolved into what we currently know as the corporation.

\subsection{The Dutch East India Company}

At the end of the sixteenth century, the Dutch started to employ variations of the commenda-so-called voorcompagnieën or pre-companies-in order to scale up the Dutch Asian trade journeys. These early pre-companies consisted of a number of commendas, each with its own investors and active merchant. With wars and conflicts with the Portuguese and the English, there was an urgent need for an integrated approach. In this regard, the city-based pre-companies, which faced fierce competition for market share, decided to coordinate their actions by conducting a kind of merger in 1602, which led to the inception of the Dutch East India Company (Vereenigde Oostindische Compagnie (VOC)). Gradually the VOC evolved into a peculiar form of the current corporate form. ${ }^{8}$ With the transformation of the VOC came a change not only in organizational form, but also in the venture's investor base (see Fig. 1).

At the same time, cities, in order to coordinate and structure the collaboration between the independent pre-companies, created a charter which dealt with potential collective action problems and conflicts of interest. Despite these governance reforms, investors often expressed their dissatisfaction and frustration with dividend policies, the murkiness of the company's accounts, and the lack of disclosure and transparency. ${ }^{9}$ Other problems for investors were the limited involvement of the main board of directors - the Board of Seventeen Lords (De Heren XVII) — which convened only a few times a year and directly reported to the Dutch governmental authority rather than to investors.

It appears that the design of the VOC, despite the key features of limited liability and readily transferability of shares, made this business arrangement prone to fraud and deception. In response to these shortcomings, the government mandated full and open disclosure of accounts in 1622. Subsequently, the committee of nine and audit committee, an early form of the supervisory board consisting of 'chief participants', being significant investors, were introduced in 1623 to advise management and inspect the financial information of the VOC. With these major changes in the VOC structure, the first 'corporate governance' movement was initiated. Nevertheless, it could not solve effectively the problems surrounding the complex and cumbersome management structure inherent to the VOC arrangement.

\footnotetext{
8 McCahery and Vermeulen (2008).

9 De Jong and Röell (2005).
} 


\subsection{The Mississippi Company and South Sea Company}

The precarious nature of the early corporate form was again exemplified by the collapse of the French Mississippi Scheme and the burst of British South Sea Bubble in 1720. The Mississippi Company and South Sea Company succeeded in attracting shareholders and creating a robust market for their shares by manipulating information and talking up share prices with rumors and speculation about the companies' value and prospects. In France, domestic and foreign investors were lured into the scheme by the sheer fact that the government granted the corporation monopoly control of Louisiana, which was conceived as the actual key to unlimited wealth creation. The government and the Mississippi Company kept the investors' imagination baffled with vague objectives to promote immigration and control the tobacco industry until confidence collapsed and the corporation ceased to exist, ruining the lives of many disappointed investors throughout Europe.

For the same reason people rushed to invest in the British Company which was granted 'important' monopolies over English trade in South America. However, vital information about the Spanish being in control of these regions was concealed from the potential investors. The South Sea Company was in fact nothing more than an empty shell without any future cash flow and expectations.

Of course, the deflation of the bubbles fueled an anti-corporate sentiment and chilled the investment interest of the public, but the corporate form never disappeared completely. Even though the corporate form was only available to certain types of businesses due to the formal concession of a sovereign person or government, its organizational and structural advantages — such as continuity of life, the possibility to sue outsiders and members in its own name, the distinction between the corporation's assets and the personal assets of its shareholders, and the transferability of shares-prevailed over its susceptibility to fraud and abuse.

\subsection{The Industrial Revolution}

In fact, the corporate form became a success story. That much seems clear from even the most cursory review of the history of corporate law. Moreover, the corporate form became the driving force in the growth of capitalism. An editorial from The Economist of December 18, 1926 makes this point succinctly:

The economic historian of the future may assign to the nameless inventor of the principle of limited liability, as applied to trading corporations, a place of honor with Watt and Stephenson, and other pioneers of the Industrial Revolution. The genius of these men produced the means by which man's command of natural resources has multiplied many times over; the limited liability company [provided] the means by which huge aggregations of capital required to give effect to their discoveries were collected, organized and efficiently administered. 


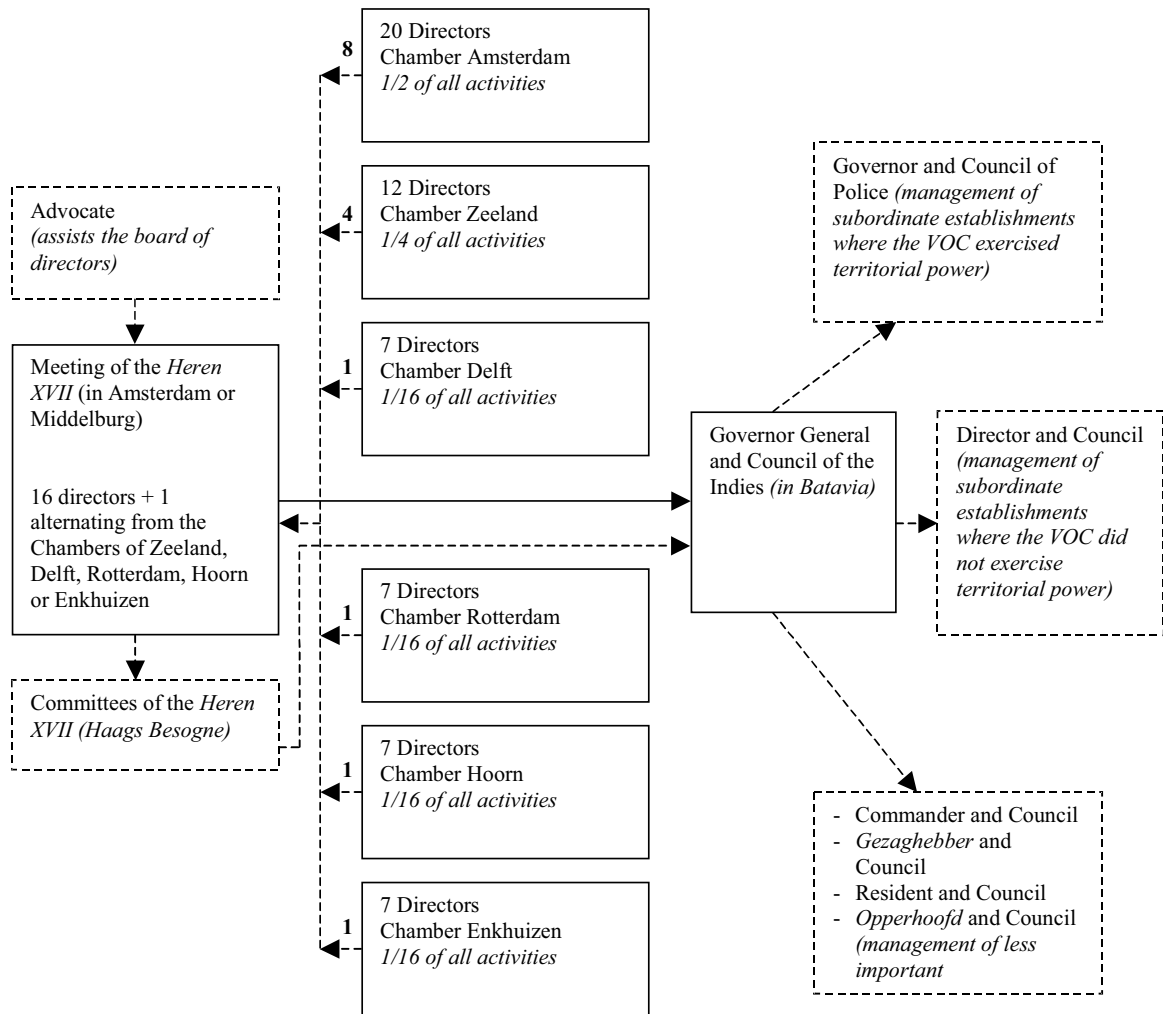

Fig. 1 The Organization of the VOC. Source: http://www.tanap.net

As capitalism developed, numerous firms were incorporated for the purpose of building roads, canals, railroads, and telegraph lines. The improved transportation and communication infrastructure created by such firms facilitated the proliferation of other corporations that produced the consumer goods and services that came to dominate industrial economies.

In general, such firms benefited from three management-finance principles offered by the corporate form: (1) the corporate form is a legal entity which exists separately and independently from its founders, managers and shareholders; (2) centralized, specialized and professional management offers improved performance, since professional managers are better placed to streamline operational processes within a firm; and (3) limited liability allows a relatively large number of investors to diversify risk and trade their shares publicly. In this way, the corporate form provided the framework by which capital was able to combine effectively with entrepreneurial spirit for the benefit of society.

With the growth of commercial and industrial activity in the nineteenth century, the pressure from politically influential industrialists to make the corporate form available to all, and not just through entities receiving a governmental charter, grew steadily in most industrialized countries. The expanded use of 
the corporation and the further development of the common law of corporations resulted in increasing demands for codification measures in common law jurisdictions in the nineteenth century. For instance, by 1890, all states in the United States had adopted statutes that made the corporation-with the limited liability feature-easily accessible by means of a simple process of registration. ${ }^{10} \mathrm{Such}$ corporate law statutes were mere restatements of the law as developed in practice by the customs of merchants and the courts.

During the same era, civil law countries followed a different codification approach. In the spirit of revolution rather than evolution, judge-made law was viewed with suspicion and as a means of upholding the pre-codification regime. The lawmaking authority shifted from judges to public legislatures (established by constitutional documents and principles). These legislatures severed all ties with the past when engaged in their codification efforts. As a result, the corporate law statutes in common law and civil law jurisdictions differed significantly in features dealing with similar issues, reflecting the different methods of codification. More than their common law counterparts, the drafters of corporate law statutes in civil law jurisdictions attempted to mitigate the (potential) governance failures and errors by tightening the rules, giving the statutes a more mandatory character in terms of protection of shareholders' and creditors' rights.

With the tightening of the rules and regulations for publicly held corporations at the end of the nineteenth century and more generally in the twentieth century as a result of recurring stock market bubbles and economic recessions, lawmakers in civil law countries were forced to innovate. The convoluted and mandatory nature of the law had made the corporate form impossible to use for smaller companies. In order to improve the business environment for the more entrepreneurial and risky companies, civil law jurisdictions started to discuss and introduce separate private corporate law statutes for non-listed small- and medium-sized enterprises.

\subsection{The Focus on Small- and Medium-Sized Enterprises}

Germany is renowned for the enactment of the first private corporate form, i.e. the Gesellschaft mit beschränkter Haftung $(\mathrm{GmbH})$, which was introduced on 19 May 1892. The private corporate form provided active investors in small- and mediumsized enterprises with limited liability protection without having to abide by the onerous rules designed to protect passive investors in listed companies. The introduction of the GmbH-form, and its subsequent transplantation throughout the European continent, as well as in Asian and Latin-American civil law jurisdictions, is considered an important development in the history of corporate law (Table 1). Arguably, it challenges the superiority of common law systems. Nonetheless, the introduction of new business forms tailored to the needs of non-listed firms/MSMEs should not be looked at in isolation.

Consider the development of corporate law in Delaware, which is the most popular state of incorporation in the United States. It is indeed true that Delaware (and

${ }^{10}$ Blumberg (1986). 
the other states) were a 'laggard' in terms of adopting a separate corporate business form for non-listed companies. However, for reasons of flexibility in the incorporation and operation of businesses, both listed and non-listed companies started to avail themselves of the corporate form. Contractual deviations from the rigid corporate structure were used to tailor the corporate form as much as possible to the needs of small- and medium-sized non-listed companies. The fact that the initial tendency of courts was to treat these contracts with suspicion (by rendering shareholder agreements that provided the parties with partnership-type governance invalid) did not stop corporate lawyers from deviating from the general corporate law statutes by opting out of stricter rules that negatively affected the operations of their corporate clients. The lawyers' drafting persistence gradually resulted in courts allowing the use of contractual arrangements despite the possible tension with the corporate structure.

For example, corporate lawyers, attentive to the specific needs and aspirations of fast-growing high-tech firms, often advise their clients to incorporate in Delaware. Delaware's statutory law and case law permits the lawyers to contract around irrelevant and inconvenient default rules and tailor rights and duties that are more consistent with their organizational priorities. These contractual arrangements, set forth in the articles of association, stock purchase agreement, investor rights agreement and other legal documents, arguably offer an effective, although second-best, solution to the challenges of investing in high-tech companies. ${ }^{11}$ Indeed, venture capital investments in start-up companies are optimally made against the issuance of convertible preferred stock, which allow for significant ex post flexibility in the determination of control rights and the conditions upon which venture capitalists are allowed to exit their investment. Convertible preferred stock is considered optimal because it secures downside protection for venture capitalists and gives entrepreneurs incentives to take significant risks in order to obtain a higher final firm value in the event of success. There is little doubt that the flexibility of Delaware's General Corporation Law-in that it allowed corporate lawyers to experiment with innovative contractual provisions that encouraged venture capitalists to actually invest in start-up firms and at the same time stimulated a steady supply of entrepreneurs-has also been a key input to the development of the venture capital industry in the United States. $^{12}$

In contrast, statutory corporate law in civil law jurisdictions usually lacks the flexibility of Delaware law. ${ }^{13}$ Private corporate law in Europe, for instance, in many respects a mirror image of the law for public corporations, was generally characterized by its mandatory nature and inflexibility, leaving little room for legal experimentation and innovation. Yet, path-breaking decisions of the European Court of Justice, resulting in the improvement of the so-called 'incorporation mobility', have dramatically altered the continental corporate law

11 Callison (2000).

12 Gilson (2003).

13 McCahery and Vermeulen (2004). 
Table 1 Private companies in civil law jurisdictions Source: Adapted from Lutter (2007)

\begin{tabular}{|c|c|c|c|}
\hline Country & Name & Year & Remarks \\
\hline Argentina & Sociedad de Responsabilidad Limitada (S.R.L) & 1932 & \\
\hline Austria & Gesellschaft mit beschränkter Haftung $(\mathrm{GmbH})$ & 1906 & \\
\hline Belgium & $\begin{array}{l}\text { Besloten vennootschap met beperkte aansprake- } \\
\text { lijkheid (BVBA) }\end{array}$ & 1935 & Modeled on the partnership form \\
\hline Bolivia & Sociedad Limitada (S.L.) & 1941 & \\
\hline Bulgaria & Druzhestvo z Ogranichena Otgovornost (OOD) & 1924 & \\
\hline Chile & Sociedades de responsabilidad limitada & 1923 & \\
\hline Colombia & Sociedades de responsabilidad limitada & 1937 & \\
\hline Denmark & Anpartsselskab (ApS) & 1973 & $\begin{array}{l}\text { Introduced to avoid the applica- } \\
\text { tion of European Corporate } \\
\text { Law Directives }\end{array}$ \\
\hline France & Société à responsabilité limitée (S.A.R.L.) & 1925 & \\
\hline Germany & Gesellschaft mit beschränkter Haftung $(\mathrm{GmbH})$ & 1892 & \\
\hline Greece & Eteria Periorismenis Efthinis (E.P.E.) & 1955 & \\
\hline Hungary & Korlátolt Felelosségu Társaság (Kft) & 1930 & \\
\hline Italy & Società a responsabilità limitata (s.r.1.) & 1942 & \\
\hline Japan & Yugen-Kaisha & 1938 & Abolished in $2005 / 2006$ \\
\hline Mexico & $\begin{array}{l}\text { Sociedad Anónima de Capital Variable (S.A. de } \\
\text { C.V.) }\end{array}$ & 1934 & \\
\hline Netherlands & $\begin{array}{l}\text { Besloten vennootschap met beperkte aansprake- } \\
\text { lijkheid (BV) }\end{array}$ & 1971 & $\begin{array}{l}\text { Introduced to avoid the applica- } \\
\text { tion of European Corporate } \\
\text { Law Directives }\end{array}$ \\
\hline Paraguay & & 1941 & \\
\hline Poland & $\begin{array}{l}\text { Spólka z ograniczona odpowiedzialnoscia (sp. } \\
\text { z o.o) }\end{array}$ & 1934 & \\
\hline Portugal & Sociedade por Quotas (Lda) & 1901 & \\
\hline Romania & Societate cu raspundere limitata (SRL) & 1990 & \\
\hline Spain & Sociedad Limitada (S.L.) & 1953 & \\
\hline Switzerland & Limited liability company $(\mathrm{GmbH})$ & 1936 & Modeled on the partnership form \\
\hline Venezuela & Sociedad de Responsabilidad Limitada (S.R.L) & 1955 & \\
\hline
\end{tabular}

landscape. ${ }^{14}$ The court decisions allowed start-up firms to incorporate under the laws of other Member States if the foreign business form better serves their needs. The pressures of 'losing business' to neighboring jurisdictions gave rise to a large number of corporate law reforms to offer firms a more flexible and adaptable regulatory framework. It should be noted here that corporate law reforms are not limited to Europe. Stimulation of entrepreneurship, attraction of foreign investments and the facilitation of investor participation in local companies are all driving forces behind reform initiatives worldwide.

14 Bratton et al. (2009). 


\subsection{Corporate Law Reforms}

Corporate law of the twenty-first century thus offers a diverse spectrum of incorporation and operation options to firms. At one end of the spectrum, there is the traditional public corporate form that has become more heavily regulated in order to restore investor confidence and prevent another financial crisis. On the other end, lawmakers endeavor to provide firms, particularly non-listed businesses, with one or more flexible organizational forms that allow them to pursue entrepreneurial activities.

Illustrations of recent corporate law developments allow us to see how the reforms tend to map on the spectrum of corporate law options. Here are some of the key findings:

(1) Policymakers and lawmakers around the world are actively discussing the further regulation and control of listed firms. Some examples of this trend include the rules that are meant to promote the involvement of independent directors and long-term shareholders in the decision-making process of firms. In addition, certain policymakers have argued that changing the composition and compensation of corporate boards will deter fraud and abuse in the boardroom and, at the same time, foster firm performance.

(2) Lawmakers are considering and introducing legal upgrades to their private corporate law forms leaving the core of their legal system untouched. These reforms are characterized by compromise legislation that mainly focuses on the simplification of formation requirements. Proponents of this view are of the opinion that legal certainty arguments prevent a more ambitious reform which offers business parties an environment of private ordering and contractual flexibility. The private corporate law reforms in the European Member States are examples of such compromise reforms.

(3) Corporate law reforms are also moved by interest group pressures with the effect of the promulgation of new hybrid business vehicles that combine the best features of the traditional partnership and corporate forms. The key drivers behind the development of new business forms are the benefits of maximum flexibility and autonomy of business parties to structure the firm's internal organization free from historically determined rules and doctrines. It is to be observed that the introduction of new hybrid business forms has the potential drawback of being a relatively untested entity that has not generated a large body of case law and academic research. However, such statutory incompleteness is often mitigated by (1) developing improved statutory default rules to provide enhanced certainty and guidance to the business parties, (2) initiating regularly updates of the business law statutes and (3) providing model articles of association on a 'think-small-first' basis that offer, particularly, smaller firms 'off-the-rack' provisions reflecting the preferences of the majority of users of the business form, thereby reducing transaction costs. The Limited Liability Company in the United States, the Limited Liability Partnership in the United Kingdom, the French Société par Actions Simplifiée (F-SAS), and the Colombian Sociedad por 
Acciones Simplificada (C-SAS) are examples of such innovative hybrid business forms.

(4) The success of hybrid business forms also inspired legislatures in other jurisdictions to implement hybrid business form legislation. For instance, limited liability partnerships were introduced in other common law jurisdictions, such as Singapore and India, to expand the governance options to be considered by small- and medium-sized businesses and professionals. Japan, which has a tradition of following Germany's civil law system, also introduced new hybrid business forms in 2005 and 2006. The rationale behind this was to supply Japanese firms with more contractual flexibility, thereby encouraging the establishment of multinational joint ventures in the human capital-intensive and financial services sector. The developments described here can be distinguished from the introduction of hybrid business forms in the United States, the United Kingdom, France and Colombia in that the lawmaking initiatives were undertaken by public legislatures or groups affiliated to public state actors.

Important observations can be distilled from these developments: (1) in general, lawmakers are reactive, rather than proactive. They are reluctant to take action before an actual problem has occurred and tend to only respond to facts and competitive or interest group pressures; (2) reforms are significantly different, making 'harmonization' a difficult, if not impossible, endeavor; (3) 'compromising' between approaches is also difficult, particularly given the differences between common law and civil law approaches; (4) 'linking' would have the disadvantage that the resultant linked organizational form would be like a chameleon offering differing solutions in each donor jurisdiction.

In the following, we want to suggest that the answer to the question of the best approach in this context can be found in 'responsive lawmaking'. The following section briefly discusses the different lawmaking approaches and how they could function at an UNCITRAL level, in more detail.

\section{Responsive Lawmaking}

Given the above context, what can UNCITRAL contribute? Rather than focus on existing regulation of small business and aim at harmonizing or simplifying what is already there, it is preferable to build from the 'bottom-up' by first identifying the needs of small business and then developing a legal framework that aims at best meeting those needs. Advocating such an approach involves an acknowledgment of the limitations of the current regulatory approaches, so we begin by identifying these limitations before considering the main features of a 'responsive lawmaking' approach.

\subsection{Limitations of Uniform and Compromise Legislation}

Given the interest in promoting cross-border trade, commentators often point to the importance of harmonized or uniform legislation. According to this view, the 
benefits of harmonized or uniform organizational laws probably outweigh the benefits of competitive lawmaking and firms' flexibility in choosing an optimal jurisdiction. Uniform laws, which are recommended for adoption in more jurisdictions, may have several advantages. If they are widely adopted by the states, transaction and information costs will be reduced. Uniform rules have the advantage of simplicity and lower administrative costs. They are also more appealing to the extent that the benefits of regulation are the same for all firms across a region. As a result, uniform laws help to encourage cooperation between firms situated in different jurisdictions. In addition to immediate benefits for firm participants, including investors and creditors, uniform laws are typically drafted with great care by panels of experts, thereby offering consistency in lawmaking. Finally, uniform laws have the potential to provide focal point solutions to coordination problems among jurisdictions. If uniform laws are viewed as being drafted by a group of experts and academics that takes into account the minimum needs of all of the states to an equal degree, these laws provide a prominent solution for coordinating behavior. When more states have adopted the uniform solution, it becomes harder for other states to stay behind and attempt to attract firms by offering lax legislation.

The above considerations suggest that uniform-law drafters promulgate welldesigned and theoretically appropriate legislation. Yet nothing seems further from the truth. A closer look at uniform lawmaking process shows that uniform laws reflect a strong status quo bias. Moreover, interest groups often have a strong incentive in influencing the work of uniform lawmakers. Since the drafters of uniform laws are especially interested in the uniformity of the law, they have a clear interest in producing laws that will be implemented by as many legislatures in as many countries as possible.

As a consequence, uniform laws often focus on relatively simple issues that general legal expertise can resolve rather than controversial law reforms that require special expertise in a given subject. In addition, since the success of a uniform law depends on its implementation in as many countries as possible without amendment, the uniform lawmaking process usually does not tend to instigate radical reforms that legislatures are unlikely to enact. In other words, it is a better strategy for 'uniform lawmakers' to distil the common denominator of the laws of various countries and to leave aside controversial subjects. This type of compromise legislation is particularly true if and when discussions about legal doctrine dominate the lawmaking process.

\subsection{The 'Second-Best' Option: 'Linking'}

Given the significant shortcomings of uniform and compromise legislation, lawmakers could contemplate the introduction of a new business form, which is explicitly linked to the traditional corporate law framework. The advantage is that this strategy has the potential to lead to genuine change that will increase the overall quality of law for firms generally. A linked, but new, legal business form holds out the prospect of superior cost advantages due to better suited statutory provisions without 
the difficult and time-consuming 'legal doctrine' discussions that usually surround harmonization and compromise legislation.

There are many successful examples of this 'lawmaking strategy' in France (Société par Actions Simplifiée), the United Kingdom (Limited Liability Partnership) and Colombia (Sociedad por Acciones Simplificada-C-SAS). The Colombian experience is particularly important in the context of this paper, since its main focus is on MSMEs.

The impact of the C-SAS has been astonishing and it has ushered in a new way of doing business in Colombia. Interestingly, its flexibility and easy and cheap access to limited liability not only the eclipsed 'sole proprietorship' as a form of doing business, but also gained substantial market share compared to traditional corporate law forms, such as the private corporate form and the stock corporation.

Not only did the new law create a new organizational form, but its enactment method was innovative as well. The bill did not attempt to reform existing corporate law legislation contained in the Commercial Code but instead created a completely new law. As mentioned, this method wisely avoided prolonged dogmatic and doctrinal debate aimed at preserving the status quo. A completely new bill allowed the stability of older more predictable laws to survive along with the ultimate flexibility offered by the C-SAS. Topics that were not covered by the C-SAS Act were referred to (linked to) the existing corporate law regimes.

Business parties can establish a C-SAS by filing a simple registration before the Chamber of Commerce (without going through the complicated and timeconsuming incorporation requirements that apply to the traditional organizational forms, such as the mandatory rule to have a multiple number of shareholders and the appointment of fiscal auditors). The Act made it clear that shareholders would be shielded from any liability concerning any obligations arising from the business activities of the corporation. Furthermore, it removed obsolete prohibitions regarding the activity of shareholders and managers and, most importantly, adopted the straightforward principle of freedom of contract. It is now, for instance, possible for shareholders to manage the company directly and/or obtain different classes of shares. The new law even introduced an innovative and alternative enforcement mechanism, which referred conflicting parties to an arbitration or administrative adjudication procedure. The simplified incorporation procedure allowed the Chamber of Commerce to design an online system that facilitated the electronic filing of new C-SAS registrations.

Currently, the incorporation process can be completed in less than two hours. This is because the website of the Chamber of Commerce of (for instance) Bogota provides a six step process: (1) the creation of an account, including the application for a corporate name and tax ID-number; (2) the filing of the articles of incorporation (in order to expedite the process, model articles of association are made available); (3) the online payment; (4) the request to issue a digital signature; (5) digitally signing the incorporation documents; and (6) review of the documents by the Chamber of Commerce. ${ }^{15}$

${ }^{15}$ Reyes (2015b). 
A wide range of businesses employs the C-SAS. In only 4 months the C-SAS was the preferred business entity in Colombia. Ever since, the C-SAS has continued increasing its market share. The C-SAS comprised more than $90 \%$ of the new business formations by the end of 2011. What is surprising is that, besides the smallest companies and family firms benefitting from the dual class shares, international corporate groups, looking for cost-saving opportunities, rushed to convert their subsidiaries into this new business form. What was thought to be a small to medium business solution has proven flexible enough to also satisfy the needs of large multinational businesses. In fact, there are approximately 1000 large enterprises incorporated as a C-SAS. Therefore, this type of entity is ranked second amongst large businesses forms only behind Stock Corporations (sociedad anonima). With nearly 5000 large business entities in Colombia, the C-SAS comprises roughly $20 \%$ of the largest enterprises.

Thus far the C-SAS' growth has been phenomenal. Registered entities grew from $33 \%$ in 2010 to over $56 \%$ in 2011 . This indicates that the significant surge in registered corporations can overwhelmingly be attributed to the success of the C-SAS. An examination of the C-SAS monthly growth also confirms this conclusion. In 2009, the average number of C-SASs created per month was 1516. The next year, 2010, it almost doubled to 3120 per month. As of 31 January 2012, a total of 135,641 C-SASs were registered in Colombia, with over 5100 registered in January alone.

Despite the success of the C-SAS, however, this process of linking can involve significant costs (e.g., increased information costs and uncertainty, distortions in the signaling function of organizational forms, decreased coherence of terms, erroneous gap-filling by courts and negative spill-over effects). Such costs can outweigh possible linking benefits. Here it should be noted that the cost of linking will not be high for MSMEs, because their governance structure is in general relatively simple and straightforward. This also explains why these costs have only played a minor role in the organization form decisions in Colombia. The bigger issue for UNCITRAL is that it is almost impossible to draft a 'linked' simplified corporate form without having a pre-existing corporate legal system to refer to. Recall that UNCITRAL is not bound to any legal tradition.

From UNCITRAL's perspective, drafting a legislative guide or model law for a separate organizational form would be the preferred strategy. In this respect, a distinct statute not only helps to define the firm participants' expectations ex ante, but could also assist judiciaries and arbitrators in filling gaps in the statute or the parties' contracts ex post. Furthermore, a separate legal framework for the smallest and simplest firms would make is easier for jurisdictions to adopt the new organizational form (because they do not have to deal with the cumbersome and complex issue of achieving effective linkage with a pre-existing set of corporate legal norms and legal tradition).

\subsection{Towards 'Responsive Lawmaking'}

A new UN-backed organizational form should offer a stand-alone, standard-form and contract-based solution that can help to economize on transaction costs such as drafting, information and enforcement costs, and to limit opportunism and fill gaps in the relational contract between the business participants. From this perspective, 
organization law offers a model/framework that governs the relationships between the participants inside the micro-firm and the representation of the firm in their dealings with outside participants, such as creditors. In this respect, it is important to recall the 'think-small-first' principle, but also to accommodate small- and mediumsized enterprises with high-growth aspirations. In general, such a business-friendly statute acts as a set of 'off-the-rack' terms upon which all participants can fall back when establishing the distribution and allocation of powers and responsibilities for varying levels of control and commitment.

Instead of taking existing corporate law statutes and doctrines as a starting point, a more effective approach is to start with a blank slate by first focusing on the business needs of entrepreneurs. Two basic principles should guide deliberations on these issues. Firstly, at all times it is important to remain focused on the real world needs of entrepreneurs operating MSMEs, and to focus on the issue of what the law can do in order to satisfy those needs. The alternative approach is to meander towards a compromised and uniform framework based on pre-existing (and competing) models. Satisfying the needs of the entrepreneur must be the overriding consideration in any decision as to the appropriate legal rule or standard, as well as the overall framework.

Secondly, in designing a legal framework that facilitates entrepreneurs in their business activities and aims to integrate them into the formal economy, the law must satisfy their expectations, but it also must protect them against circumstances or events that they do not necessarily foresee. This second principle is not incompatible with an overriding emphasis on the needs of entrepreneurs, but involves acknowledging that entrepreneurs may not always be in the best position to foresee every possible need, particularly negative eventualities, and that protecting against such risks is an important aspect of regulatory design in this context.

Despite its advantages, the introduction of a UN-backed organizational form will almost certainly be called into question from various constituencies. In this sense, the practical usage of such a UN initiative seem limited. There are several reasons for this. For instance, the introduction of a new organizational form may be conceived as confusing and untidy, thus increasing uncertainty, unpredictability and inefficiency. Others will consider a new organizational form as overlapping, repetitious and redundant. Finally, a new form might be seen as not making sense, since it offers little that could not yet be achieved within the traditional menu of organizational law forms. Indeed, the existing private corporate law forms are often viewed as all-purpose vehicles that, on the one hand, may bear a strong resemblance to partnership-type firms and, on the other, facilitate enterprises that bring together passive investors and active managers. In the event of stakeholder failing to deviate from the corporate rules and governance structures, courts arguably act as a safety net and interfere if the context of the facts of a case so dictates.

Indeed, in order to meet the needs of the specialized and idiosyncratic relationships in private firms, legislative and (more importantly) judicial adaptations and additions to the analogy of partnership law have been made in a piecemeal fashion across jurisdictions through the years. For instance, in Germany and in some states in the United States, the judiciary has recognized that shareholders in a close corporation setting may owe each other a strict partnership-type fiduciary duty of good 
faith and loyalty. In the Netherlands, for instance, the Dutch Supreme Court articulated strict restrictions on interest transfer for shareholders of close corporations, based on enhanced good faith and fiduciary duties, where the articles of incorporation did not explicitly address these matters.

Also, in Ebrahami v. Westbourne Galleries, ${ }^{16}$ the House of Lords decided that circumstances in which a UK private corporate form is in essence a quasi-partnership (formed and continued by individuals who were essentially partners but who had chosen the corporate structure for its limited liability protection). The presence of the circumstances justified the application of the just and equitable winding-up principles of standard partnership law. In short, the application of automatic dissolution and buy-out rights, strict precepts of fiduciary duty and good faith to protect shareholders, the authorization of strict share transfer restrictions, and contractual flexibility to modify and sidestep rigid rules characterize the private corporate form as a 'quasi-partnership', 'incorporated partnership', or 'partnership corporation'.

There is something to the view that traditional corporate forms would be sufficient to deal with the special needs of MSMEs. In fact, it could be argued that most corporate laws (partly due to the increased competition amongst jurisdictions) offer parties sufficient flexibility to customize the governance structures with MSMEs in mind. The popularity of the traditional 'private corporate' type organizational form in most countries in the world seems to proof this point.

However, here it should be noted that there is still confusion about the nature of private corporate forms. Clarity on this topic has been hindered by a patchwork of regulatory reforms and judicial interventions. The nature of the academic discussion does not always help: while many commentators view the 'mom and pop' firm as being the archetypical private corporation, others point to a wider range of MSMEs that employ the corporate form, such as high-tech operations backed by sophisticated outside investors. ${ }^{17}$ They argue that although the traditional corporate form does not meet the needs of the 'typical' small firm, its structure is especially well-suited to scaling high-tech firms, which are characterized by a high proportion of 'match-specific assets'. In their view, it is more efficient to expand the menu of business forms with a specific MSME-focused entity so as to allow private corporate law to maintain its distinctive hierarchical 'corporate' qualities which are built around the principle of centralized management. Indeed, the focus of corporate law is on the regulatory design of 'checks-and-balances' in hierarchical organizations in which authority and empowerment flows from the shareholders-who are viewed as the owners of the firm - through the board of directors to management and eventually staff (see Fig. 2).

It is not surprising that Larry Ribstein suggested that it might be time for a fundamental re-evaluation of organizational law and, perhaps, recognition that an 'uncorporated' limited liability form offers a better way. By embracing this strategy, 'un-corporating' (instead of regulatory design of 'checks-and-balances' in hierarchical organizations) can offer a powerful new framework for thinking about an

${ }^{16}$ Ebrahami v. Westbourne Galleries [1973] AC 360, [1972] 2 All ER 492.

17 Rock and Wachter (1999). 
MSME-form in a contemporary context. This involves asking: What kind of legal rules or standards should govern this uncorporated limited liability organization? In order to answer this question, the next section will first discuss the real world needs of MSMEs in the twenty-first century.

In practice, the main difference between traditional corporate forms and the United Nations Limited Liability Organization (UNLLO) is the level of hierarchy. The new corporate form is designed to deal with some of the issues that are created by hierarchical organizational forms. In this respect, the UNLLO takes the conception of 'flat-hierarchy' as a starting point. Achieving such a flat-hierarchy depends on the active participation of everyone inside the firm. If we accept that flat-hierarchy is important and relevant in the context of MSMEs.

\section{Core Elements of MSME-Organizations}

What then really matters for MSMEs? What are the key elements of such a business form and what do entrepreneurs operating such businesses really need? What is important to them? What do they do? From our perspective, the crucial feature of MSMEs is that they adopt informal and non-hierarchical structures and practices. Moreover, they want to retain this informal character, even after-or even, especially after-they enter the formal economy.

Based on an empirical review of the needs of small-scale entrepreneurs operating in the informal economy, we think the following five factors are crucially important. In identifying the following factors, we focused on three types-or modelsof 'entrepreneur'. Of course, a tremendous degree of diversity exists between the different types of business that we considering, but identifying common needs that exist between the following 'paradigmatic' types of business can give the discussion a structure that expedites the task of identifying appropriate legal structures relevant for all such cases.

The three 'paradigmatic' cases that we take as representative of the range of needs that should be considered in developing an entrepreneur oriented law are as follows: Firstly, there are street vendors operating in urban public space in emerging markets who are offering easy access to a diverse range of goods and services. Although such vendors are usually operating outside the formal economy, such vendors may have strong links to the formal economy, in that the source of their goods is the formal economy and most of their customers are operating in the formal economy. In addition, street vendors may be creating multiple jobs-either directly or down the supply chain-and they can provide an important source of public revenue, via licenses, taxes or fines. As such, they are a paradigmatic example of what the literature on the 'grey' economy refers to as 'informal micro-entrepreneurs'.

A second paradigmatic case-also an informal micro-entrepreneur, albeit of a different type-is the case of a mobile 'app' developer, either comprising one individual or a small team of developers. With the global proliferation of smart phone mediated communications, the technical resources to develop apps are now available to all online. The key challenge is to have a great idea and the commitment to develop that idea. The proliferation of smart phones-in both 


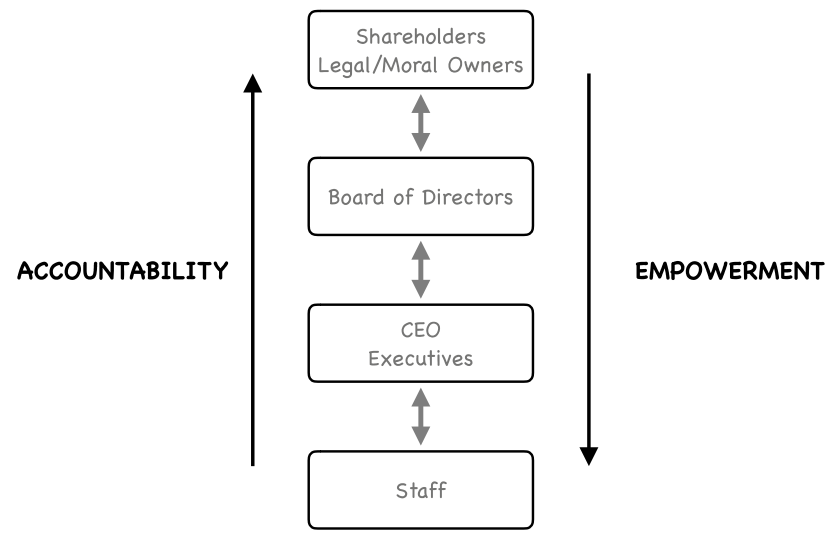

Fig. 2 The Organization of the Corporate Form. Source: Brown Dog Consulting, http://www.brown dogconsulting.com/

emerging and developed economies-means that the potential market for such applications is enormous. As with street vendors, app development is a form of entrepreneurial risk-taking activity that has the potential to be transformed into a growth-orientated and wealth-enhancing business venture.

Finally, there is the case of a small firm in the informal sphere that is looking to enter the formal economy in order to scale up. The type of firm in this context does not matter; the key point is that such a firm is operated by entrepreneurs who are producing goods and services but which has no legal existence and, as such, is unregulated by any legal framework. Established small businesses of this kind use the informal economy in an on-going way, primarily on the grounds of convenience, i.e., as a strategy for 'getting by'. Many such firms engaged in the informal economy are displaying entrepreneurial talents, skills and endeavor that could be harnessed in order to encourage such firms in their ambitions to expand.

What then are the shared 'real world' needs of these three diverse business forms operating in the informal economy, i.e. what are the principles that should guide organizational design in the twenty-first century?

\subsection{Identity and Visibility}

All of the above entrepreneurs need their business to have an identity that can facilitate market recognition and allow third parties to more easily deal with them. As such, a formal legal identity can provide a 'face' to show to rest of the world, both in terms of easing transaction costs and developing branding. An independent identity can be used in dealing with the rest of the world andin doing so-become a source of new opportunities that can add value to the business. 


\subsection{Certainty and Protection}

Entrepreneurs want certainty and protection regarding the allocation of property rights. For example, in the case of the app developers, they want to know that their partner is not going to be in a position to take any code or prototype that is developed. A clear assignment of ownership-i.e., who owns what?-and asset partitioning becomes crucial. Moreover, it is also important for entrepreneurs to separate business assets from personal assets, and to ensure that private assets are ring-fenced from any potential claims of creditors.

\subsection{Power and Control}

Most entrepreneurs, particularly single entrepreneurs, want a 'one-tier' organization in which there is no separation of ownership and control, or centralized management. The organizational form needs to preserve the principle of 'ownermanagement' and not require any delegation of management functions. That is not to say, that when they grow and professionalize, they prefer to have centralized management and-perhaps even-a board of advisors. But since think small first is key principle, the one tier version should be the default. Certainly, deviating from the default is sometimes easier said than done. The law should therefore provide some guidance.

\subsection{Flexibility and Opportunity to Change}

Finally, entrepreneurs want flexibility in how they operate the business, particularly in terms of how they develop the business over time. This can mean flexibility in terms of hiring new people to the business or removing people, but it can also refer to the flexibility needed in the building of capacities and the kind of mechanisms employed to reduce and manage conflicts. Finally, flexibility extends to later phases of the life cycle of the business organization, notably in terms of facilitating dissolution or acquisition of the organization.

\subsection{Simplicity and Speed}

In the administration of business, simplicity and speed are crucial. In this context, networked technologies offer enormous potential benefits. A connected app can, for example, be used in order to complete payments, as well as balance sheets. Moreover, all of the firm's operating documents need to be simplified so that they can be easily and quickly completed.

What is important to realize is that, to be effective, the UNLLO needs break with traditional ways of doing things within corporate law. Two points of difference seem particularly important in this context. Firstly, the brief history of corporate law outlined above shows us how the law regulating companies emerged out of a hierarchical relationship between passive capital and active management. 
However, we live in a world where hierarchy is viewed with a certain degree of skepticism, and organizational law should no longer be mainly or only concerned with ensuring a clear allocation of responsibility and accountability between 'unequal' partners. Rather, organizational law needs to be concerned with bringing responsibility and accountability together, and thinking of compliance with legal norms as an opportunity for companies to grow, rather than as a means of monitoring agency relationships. In this regard, it is important to break with the hierarchical frame and embrace 'flatter', less formal ways of thinking about the various relationships amongst stakeholders in a corporation.

Crucially - and this is the second way that the UNLLO is a break from the corporate law tradition - this has to be done in plain, easy to understand language that facilitates entrepreneurs in doing business. Statutory terminology needs to be clear, simple and accessible, and not drafted in traditional 'legalese'. This may involve adopting language that has not been traditionally employed in a corporate law context, but such an open approach to drafting can better facilitate the goal of UNLLO, which is to maximize opportunities for entrepreneurship and to facilitate business creation and growth.

\section{Elements of an 'Un-corporated' Limited Liability Organization}

The above discussion highlighted some common needs central to an entrepreneuroriented and responsive form of corporate lawmaking. How then do we satisfy the needs of the diverse range of entrepreneurs considered above? What legal form does the UNLLO need to take in order to best meet the needs of entrepreneurs? What legal framework should regulators opt for in addressing this issue? The headline thought in the following attempt to answer these questions is that the law should aim to facilitate what entrepreneurs need and expect and protect them against what they cannot foresee. And then-based on this approach — we would be better placed to identify the rules and standards around which any law in this field should be structured.

\subsection{Rules versus Standards}

The first issue that lawmakers need to ask themselves is whether UNLLO's statutory provisions should be drafted as open standards or specific and narrow rules. ${ }^{18}$ Although the costs of promulgating rules exceed those of drafting standards, rules can more effectively internalize many of the transaction costs. In this respect, the benefits of rules are twofold. First, firms may spend less in familiarizing themselves with the content of the law. Second, firms can become better informed about rules compared with standards and thus better conform their expected behavior when they opt into the UNLLO.

18 Kaplow (1992). 
Plain language (i.e. non 'legalese') default rules are typically economically efficient for small businesses in which all parties/actors are active participants. Three reasons explain the efficiency effects. First, economic actors who choose to do business in a joint ownership relationship without contemplating a business form or formalized agreement will likely find in the statute what they would have agreed upon had they negotiated a relational agreement. Second, the majority of business parties who intentionally opt into the UNLLO business form need not contract around the particular rules. Third, since the default rules mimic the hypothetical provisions that a majority of parties would have bargained for if they could contract without cost, opting into a business form statute functions as a substitute for private bargaining, thereby reducing transaction and litigation costs.

In practice, ventures of different varieties and complexities could fall within the ambit of a set of rules. Parties may choose an organizational form with little information about each other's commitment and trustworthiness. Because of this asymmetry of information and the consequential incompleteness of the relational contract, it has been argued that ex-ante majoritarian default rules may not always be desirable. In such a case, it becomes necessary to promulgate open-ended 'trust-enhancing' standards that can either prevent conflict or assist in ex-post dispute resolution. If lawmakers allow parties to opt out and bargain around stringent standards, such as fiduciary duties, standards may work as a 'penalty default', forcing parties to reveal information about their intentions while re-negotiating the statutory provision.

Indeed, backstop rules that parties would not have contracted for can be more efficient in certain situations. That is to say that it may sometimes appear more efficient to design a default rule that forces parties to contract explicitly. These 'penalty default rules' are also appropriate to situations in which parties can act opportunistically because they withhold private information. By devising penalty default rules, such as the equal distribution rule (which will be discussed in more detail below), lawmakers can induce parties to contract around the default, simultaneously revealing information to less informed counter-parties.

\subsection{Formation}

The UNLLO is formed simply by filing the articles of organization with the Secretary of State office, Chamber of Commerce or its equivalent in any jurisdiction. These articles involve the disclosure of only a few facts, including the name and address of the firm and the name of the persons who manage and represent the UNLLO and bind it vis-à-vis third parties. Also, the articles of association should include information about the management structure of the UNLLO. Theoretically, the formation of an UNLLO should be possible without professional assistance. Moreover, entrepreneurs should be able to create this form rapidly online over the Internet. Filed information should be publicly available upon a moderate payment.

It is thus relatively simple and cost efficient to set up an UNLLO. This makes it prone to misuse for illicit purposes, such as money laundering and terrorist financing. However, the misuse of the UNLLO can be limited by the maintenance and 
sharing of information on beneficial ownership and control. ${ }^{19}$ The UNLLO would benefit most from an up-front disclosure system, which requires the disclosure of the ultimate beneficial owners (usually the members of the UNLLO) to the authorities, Chambers of Commerce or any other institutions charged with responsibility at the establishment or 'incorporation' stage. This would also impose an obligation to update such information on a timely basis when material changes occur. The obligation to report beneficial ownership and control information to the authorities may be placed on the UNLLO or the ultimate beneficial owner. In order not to impose unnecessary costs on the establishment of the UNLLO, the beneficial ownership information will preferably not be made publicly available.

\subsection{Entity Status and Asset Partitioning}

Entity status is bestowed on the UNLLO by statutory law. An UNLLO in its own name acquires rights and obligations, acquires property and other legal rights in immovables, and can sue and be sued.

Clearly, legal entity status is a necessary shorthand device to define the property rights over which participants within a firm can contract. In the absence of entity status, it would be practically impossible to shield the assets of the UNLLO from creditors of the firm's owners. First, the transaction costs of drafting and inserting provisions in all contracts between the participants inside the firm and the firm creditors on the one hand and their personal creditors on the other will be prohibitively high. Second, the firm participants, including the business creditors, would face a moral hazard problem, viz. it is virtually impossible to assure the business creditors of the existence of the necessary agreements with the personal creditors. Finally, the entity status strengthens the firm's bargaining power vis-à-vis outsiders.

Creditors and other outsiders can then deal with the firm as a separate organization/institution rather than with the individual members. The separation between the firm's assets and the personal assets of the participants inside the firm-so-called 'affirmative asset partitioning' - is often viewed as the 'core defining characteristic of a legal entity'. ${ }^{20}$ Surprisingly, the opposite form of asset partitioning (limited liability or 'defensive asset partitioning') is not essential for the creation of a legal entity.

\subsection{Limited Liability and Capital Requirements}

Critics may question the efficiency of extending fully-fledged limited liability protection to UNLLOs. They may contend that, by virtue of their organizational structure, this new business form creates the conditions for opportunism, which may harm minority participants. More importantly, critics are concerned about risks to

19 OECD (2001) and McCahery and Vermeulen (2008).

${ }^{20}$ Hansmann and Kraakman (2000a, 2000b). 
third parties. They argue that limited liability is not wholly efficient in the context of MSMEs.

Nevertheless, it is currently widely acknowledged that limited liability fosters entrepreneurship, facilitates capital formation and protects firms against the troublesome developments in liability law. Because there is little empirical evidence to support either the efficiency or inefficiency of limited liability for MSMEs, this is a very complex question to which there is no straightforward answer. Despite the absence of evidence, most scholars find that the benefits of extending limited liability to MSMEs outweigh the costs. Here it should be noted that the uncertainty surrounding the efficiency of limited liability does not lend support to those who seek to introduce regulations, such as minimum capital requirements, to protect voluntary and involuntary creditors to the firm.

The reliance on these minimum capital requirements to balance the levels of risk-taking is deceptive. By their very nature, these requirements-which are often poorly designed and outdated-tend to impede innovation, entry and investment, and consequently create unnecessary barriers to trade and social welfare. In any event, direct creditors, which are not the main beneficiaries of such legislation, are able to bargain efficiently so as to avoid any risk that may arise in connection with any contracts involving such firms.

\subsection{Capital Structure and Contributions}

The UNLLO has members who are not obliged to make any formal capital contribution. The default rule is that the members share voting rights, profits and losses on an equal basis. The principles of freedom of contract allows deviations for the per capita sharing in which event the capital structure of the UNLLO is based on similar principles as the traditional corporate forms. The capital contribution then determines the members' voting rights, profit and loss sharing, and received distributions.

As for the consideration for the payment of shares/interests, UNLLO statutes should provide that contributions may be made to the firm in many different forms, such as tangible or intangible property or other benefits to the firm, including money, promissory notes, services performed, or other agreements to contribute cash or property, or contracts for services to be performed.

The relationship-matters such as contribution, distributions, admission and withdrawal, management, and so forth-between the members of an UNLLO is preferably governed by the 'operating agreement'. To be sure, jurisdictions may differ in their requirements regarding whether a written agreement is necessary in respect of the contribution obligations. As mentioned, the UNLLO does not require minimum contributions in exchange for a membership interest.

If the members decide to deviate from the UNLLO's default rule by including a formal capital structure, it is recommended that the members maintain a central record of each contribution to ensure the rights of members are respected. Therefore, a member could make a claim regarding a past contribution that has not been registered and seek to update the central record. Also, if an UNLLO has more than one class of interests/units, it may be necessary to create two sets of books, one that 
records the economic relationships among the members ('inside basis') and another for tax purposes ('outside basis').

\subsection{Distributions}

In general, UNLLO statutes should not demand that members receive any distribution before they exit the firm. Clearly, the law should prohibit distributions if the result of the distributions would be that the UNLLO would not be able to pay its debts and obligations. To protect creditors against excessive distributions, UNLLO statutes could include several remedies. For instance, members may become liable to creditors in circumstances they return contributions while making the UNLLO insolvent and leaving creditors unpaid. Naturally, a valuation is required to determine if the distribution entails a return of contributions in a firm that is unable to discharge its debt and other obligations. A simpler and more straightforward remedy would be a 'clawback' provision which is triggered if distributions are made, which later appear to have been made in violation of the UNLLOs' creditor protection rules.

How then will distributions be made to the members of an UNLLO? Consistent with what we have seen in the previous section, UNLLO statutes will generally include a per capita provision as for the sharing of profits, losses or retained earnings. If a member receives distributions, it is likely to be in the form of cash, but non-cash distributions are also possible.

The 'equal sharing rule' makes the UNLLO a standard form contract for the smallest and most informal kind of business arrangements, which are largely governed by social norms and economic incentives. Given the importance of human capital for the success of many smaller business ventures, the equal sharing rule is preferred over a proportionality rule in which the party's 'service' contribution is usually equal to that of the member with the smallest capital contribution. UNLLOs are typically characterized by a small number of members who participate in management and contribute substantial personal wealth to the firm, including financial and human capital. In these circumstances, equal sharing of profits and losses is arguably the majoritarian default, which at the same time corresponds to the implicit contracts and norms that govern these types of firms, and hence minimizes transaction costs for the majority of UNLLOs.

While the equal sharing rule is efficient in simple and egalitarian UNLLOs largely characterized by symmetric information and bargaining power, it appears to be a poor fit when members are not relatives or long-standing acquaintances, contribute unequal sums of capital, differ in skills or have asymmetric information. Thus seen, the equal sharing rule could be viewed as a penalizing, information-forcing default rule in all but the egalitarian UNLLOs. More legally sophisticated members who find equal sharing inappropriate will be likely to contract around the default rule if another division of the profits and losses is necessary to provide the required incentives to invest in relationship-specific assets. 


\subsection{Members' Interests}

Members' interests consist of (1) financial rights to share in the profit and losses and receive distributions, and (2) governance rights to participate in management and control. Generally, the UNLLO statute would define these rights. In the absence of contrary agreement, members may only transfer their financial rights. The governance rights may only transfer by consent of the non-transferring members.

With respect to assignments, the assignors can be released from liability when all members have given their consent to the transfer. The interests of members that pass to heirs are strictly limited to financial, but not to other rights. In effect, they are entitled to the same rights as an assignee.

\subsection{Internal Organization}

The UNLLO statute would generally provide for decentralized management ('member-managed') by default, it is also possible to opt for centralized management ('manager-managed'). This raises the issue of whether other default rules should differ according to the parties' choice. In this respect, the statute could provide for different fiduciary duty provisions, but similar dissociation and dissolution provisions.

In order to give maximum effect to the principle of freedom of contract, the operating agreement of the UNLLO may also include a board of directors. But, different from the corporate view, which is to treat the Board mainly as the supervisor or monitors of the senior managers (control of managerial misbehavior and monitoring of past-performance, compliance and sustainability), the board of directors of an UNLLO would actively contribute to the future direction and performance of the business. From the perspective of the UNLLO, the model of Board 'independence' constitutes a 'missed opportunity'. Indeed, the UNLLO seems to understand that independent directors help the firm stay relevant by including diverse perspectives that are relevant to the organization and that a more collaborative model of the relationship with management ensures when such these perspectives are incorporated into the decision-making processes in a way that adds genuine value to firm activities. $^{21}$

\subsection{Fiduciary Duties}

Fiduciary duties are moral concepts of the highest order. The keystone of the business relationship lies in the members' commitment to abnegate short-term selfinterest and to promote the welfare of the aggregate of members rather than their own. These duties are necessarily open-ended standards of performance that can be separated into (1) a duty of care and loyalty, (2) a duty to disclose information, (3) a duty to preclude from self-dealing transactions, personal use of partnership assets,

21 Vermeulen (2015). 
usurpation of partnership opportunities, and competition with the partnership, and (4) a duty of good faith and fair dealing.

In order to keep things simple and straightforward, the UNLLO should provide for a fiduciary duty that requires its 'member-managers' to act with the care that a person in a similar position would reasonably exercise under similar circumstances. By imposing a duty of care standard, lawmakers avoid ambiguities in legislation that could undermine the trust between the members in small and often family-related UNLLOs.

This brings us to the question of whether the notion of fiduciary duties should be mandatory or a default rule that the parties could tailor or waive contractually. Mandatory fiduciary duties involving less legally sophisticated actors may do more harm than good, especially when parties do not seek to completely surrender their autonomy upon becoming a member of the UNLLO. In this view, it seems more efficient to endorse the penalty default approach under which the party that suggests opting out signals their intentions. In addition, the contractual notion of good faith helps to prevent unreasonable and opportunistic contractual modifications.

\subsection{Exit}

Business parties usually do not bargain for contractual provisions that deal with dissension and deadlocks, which could suggest that these parties prefer flexible, ex post gap-filling by courts or arbitrators. For instance, judges and arbitrators could assume an easy buyout right for the dissatisfied partner if the business relationship makes the minority vulnerable to opportunistic exploitation by the majority. Nevertheless, judicial gap-filling is not only costly and time-consuming, but may also be prone to error. Judicial intervention can potentially create a judicial 'wild card' that risks creating a costly degree of uncertainty. Whilst intra-firm controversies are often observable to exasperated parties, they may not be easily verified by a judge or arbitrator, and even less so when personal relationships in the family or between friends are involved. The difficulty in predicting the judicial outcome explains why relatively few disputes seem to end up in court.

In light of the foregoing discussion, the absence of statutory guidance, which could be adopted ex ante, may have a detrimental effect on both the firm and its participants. When end-period terms are prohibitively costly to arrange ex ante by the participants themselves and are not easily verifiable by courts and arbitrators ex post, responsive legislatures appear better suited to supplying the default rules for endgame settings. As such, the logic of providing these rules is to lower costs for the parties and to create a degree of predictability that could operate as a sanction against opportunism. Because exit mechanisms provide safety nets to ensure the parties' control rights and authority over the firm-specific assets, the question of which 'default exit rule' is socially efficient is crucial. The default rule must act both as an incentive instrument and as a tool to discipline possible opportunistic abuse. These rules must be designed to contribute to the optimal governance equilibrium in the UNLLO. 
What should the UNLLO statute provide? Upon first inspection, two categories of default exit rule could be contemplated. First, parties may have the right to compel the dissolution of the firm and liquidation of its assets. Second, parties may withdraw and/or be expelled from the firm and receive the 'fair' value of their ownership interests.

Due to the high costs, policymakers and scholars argue that the 'dynamite' approach of dissolving the firm is too unstable and that a less interventionist approach could yield more value by allowing the firm to continue without triggering its dissolution. Dissociation provisions that adhere to the entity characteristic of continuity of life supply a low-cost means for firms to plan for changes in the internal organization and business environment.

This suggests that default dissociation rules represent the most optimal choice, because they are closest to what the majority would have agreed upon, had they considered the issue in advance. Indeed, empirical research shows that in many cases, independent of the default settings, one or more partners continue to operate the business. That is not to say that dissociation provisions are entirely without difficulties. Thorny calculation issues, particularly concerning the valuation of interest and whether payment should be deferred, abound in endgame settings, since the 'fair value' of interests is likely to be non-verifiable by courts or arbitrators. Consequently, it is submitted that statutory ex ante rules are best equipped to provide guidance in relation to valuation issues. For example, the UNLLO statute could take as its starting point that a dissociating member should receive the same amount in a buyout as he would if the UNLLO were dissolved. However, goodwill will be taken into account, since the buyout price is equal to the greater of the liquidation value or the value based on a sale of the entire business as a going concern. If the members do not reach an agreement on the buyout price, they can of course always have the price determined by the court.

\subsection{Open Communication}

Particularly important in the context of the UNLLO (based, as it is, on the principle of flat hierarchy) is the need for open communication between various participants. It is therefore recommended that UNLLO statutes include a mandatory 'open communication' norm. Such a mandatory norm is likely to promote an effective, lowcost landscape that generates significant benefits to the parties and other stakeholders in the UNLLO.

Indeed, an open communication norm/standard provides a mechanism by which coordinating of different stakeholders can take place. Most obviously, open communication involves a different style of information dissemination and exchange that characterizes relationships between all actors in and outside the firm. Such an approach involves acknowledging the potential benefits that accrue from a freer flow of information inside an organization, but also between the organization and those on the 'outside'. In particular, open communication is characterized by a more personalized approach to communication. 
But open communication is not only about sharing information (the one-way dissemination of information from one part of the organization to another, or from the UNLLO to external actors, most notably investors). Open communication is about building an on-going and constructive dialogue with other actors in the firm and the market that can then have a significant impact on the future performance of that UNLLO. $^{22}$

The following schematic elements of an effective standards/norm for open communication can be introduced:

- Aim for transparency and relevancy.

- Personalize, humanize and communicate a distinctive story.

- Address the 'hard' issues.

- Demonstrate leadership.

- Generate 'buzz'.

- Take advantage of alternative media.

- Monitor best practice and constantly review.

- Build relationships and invite input.

Open and 'personalized' communication is about respect (building trust and loyalty), but it is also about recognizing the material benefits that accrue from sharing. By embracing open communication, more inclusive and meaningful relationships among and between firm stakeholders can be forged. Open communication fosters a sense of belonging and expands the pool and diversity of actors with a concrete involvement in key decision-making processes. Open communication is also linked to various aspects of participation in, and responsibility for, decision-making within an organization. The most innovative firms have acknowledged that they stand to benefit from a more open attitude towards all insiders as well as outsiders, in which the class of individuals responsible for guiding the direction of the firm/organization is greatly expanded. In this way open communication can create a powerful sense of participation and belonging that makes the project more meaningful, both from the perspective of the insiders and outsiders, but also the firm.

\section{Back to the Drawing Board}

Why is now an opportune moment for UNCITRAL to be contemplating issues related to MSMEs? And what kind of approach do lawmakers need to take in seeking to draw entrepreneurial activity into the formal economy or to provide entrepreneurs with an organizational form appropriate to the twenty-first century?

In answering these questions, it is important to realize that we have passed a 'tipping point' in the legal design of organizations. The history of corporate law shows that the traditional corporate form was designed to bring together passive capital and active entrepreneurs. The agency issues that resulted from the 'separation of

${ }^{22}$ Fenwick et al. (2017). 
ownership and control' focused corporate law reform on the control of managerial misbehavior. Rules and regulations were introduced and implemented to alter, among other things, the role of non-executive directors, executive pay, disclosure, the internal and external audit process, and to sanction on managerial misconduct.

Since the separation of ownership and control is not clear in non-listed firms, these rules and regulations are poorly tailored to fit the needs of private corporate organizations. Unsurprisingly, therefore, the private corporate form emerged at the end of the nineteenth century. The regulatory framework of this form offered an innovative solution for the problems that occur in organizations with a relatively small number of shareholders, no easily-available market for the corporate stock, and where substantial 'shareholder' participation in the management, direction and operation of the firm is the norm.

Nevertheless, such private corporate forms were still built on the corporate principles of hierarchy and centralized management, which entailed that various corporate formalities, such as formal shareholder's meetings, formal formation and operation documents and extensive disclosure requirements, were still applicable.

However, continuing economic downturns and recessions have fueled an anticorporate sentiment and highlighted the shortcomings of the corporate form. For more and more people, the corporate form has become associated with a culture of self-interest and greed. The inevitable effects of corporate scandals have been feelings of dissatisfaction and frustration with the corporate form.

The answer? The above discussion has suggested that an alternative approach is preferable in which regulators and other policy makers go back to fundamentals and attempt to build from the ground up based on the real world needs of entrepreneurs in emerging markets, rather than work off already existing solutions. Indeed, in order to overcome this disconnect, it is necessary to re-visit the fundamentals of the firm-particularly, MSMEs - and to examine the meaning of these elements in a contemporary context, i.e., in the context of global markets, disruptive new technologies, entrepreneurship, etc. These elements are 'flat-hierarchy', 'open communication', 'flexibility', 'visibility', and 'speed'.

In this way, it is possible for lawmakers to engage in a more imaginative form of regulatory design in which new solutions for stimulating innovation and business creation can be developed, based on the real world needs of entrepreneurs. This paper has argued that the key to regulatory design is the adoption of a more open and flatter 'Uncorporated Limited Liability Organization' (UNLLO) that can accommodate the diverse range of business activities that are conducted by MSMEs in modern economies. In this way, opportunities for maximizing the potential for innovation, business creation and growth can be maximized.

Open Access This article is distributed under the terms of the Creative Commons Attribution 4.0 International License (http://creativecommons.org/licenses/by/4.0/), which permits unrestricted use, distribution, and reproduction in any medium, provided you give appropriate credit to the original author(s) and the source, provide a link to the Creative Commons license, and indicate if changes were made. 


\section{References}

Berman HJ (1983) Law and revolution, the formation of the Western legal tradition. Harvard University Press, Cambridge

Blumberg PhI (1986) Limited liability and corporate groups. J Corp Law 11:573-631

Bratton WW, McCahery JA, Vermeulen EPM (2009) How does corporate mobility affect lawmaking? A comparative analysis. Am J Comp Law 57:347-385

Callison JW (2000) Venture capital and corporate governance: evolving the limited liability company to finance the entrepreneurial business. J Corp Law 26:97-124

De Jong A, Röell A (2005) Financing and control in the Netherlands: a historical perspective. In: Morck $\mathrm{R}$ (ed) A history of corporate ownership around the world: family business groups to professional managers. University of Chicago Press, Chicago, pp 341-364

Fenwick MD, McCahery JA, Vermeulen EPM (2017) The future of capitalism: un-corporating corporate governance. In: Watson S (ed) The changing landscape of corporate law in New Zealand. The Centre for Commercial Law and Corporate Law, University of Canterbury Press, Christchurch, pp 63-98

Fenwick MD, McCahery JA, Vermeulen EPM (2018) Fintech and the financing of SMEs and entrepreneurs: from crowdfunding to marketplace lending. In: Cumming D, Hornuf L (eds) The economics of crowdfunding: startups, portals and investor behavior. Palgrave McMillan, London, pp 103-129

Gilson RJ (2003) Engineering a venture capital market: lessons from the American experience. Stanf Law Rev 55:1067-1104

Hansmann H, Kraakman R (2000a) The essential role of organizational law. Yale Law J 110:387-440

Hansmann H, Kraakman R (2000b) Organizational law as asset partitioning. Eur Econ Rev 44:807-817

Kaplow L (1992) Rules versus standards: an economic analysis. Duke Law J 42:557-629

Lutter M (2007) Limited liability companies and private companies. In: Conard A, Vagts D (eds) International encyclopedia of comparative law, vol XIII. Mohr Siebeck, Tübingen, pp 1-196

McCahery JA, Vermeulen EPM (2004) The evolution of closely held business forms in Europe. In: McCahery JA, Raaijmakers T, Vermeulen EPM (eds) The governance of close corporations and partnerships: US and European perspectives. Oxford University Press, Oxford, pp 191-240

McCahery JA, Vermeulen EPM (2008) Corporate governance of non-listed companies. Oxford University Press, Oxford

OECD (Organization for Economic Co-Operation and Development) (2001) Behind the corporate veil: using corporate entities for illicit purposes. http://www.oecd.org/daf/ca/43703185.pdf. Accessed 27 Sept 2018

Parker GP, Van Alstyne MW, Choudary SP (2016) Platform revolution: how networked markets are transforming the economy - and how to make them work for you. W.W. Norton \& Company, New York

Reyes F (2015a) The Colombian simplified corporation' corporate law disintermediation in a developing jurisdiction. Wake For Law Rev 50(3):743-760

Reyes F (2015b) The Colombian simplified corporation: an empirical analysis of a success story in corporate law reform. Penn State J Law Int Aff 4:392-420

Ribstein LE (2010) The rise of the uncorporation. Oxford University Press, Oxford

Rock EB, Wachter ML (1999) Waiting for the omelet to set: match-specific assets and minority oppression in close corporations. J Corp Law 24:913-948

Vermeulen EPM (2015) Corporate governance in a networked age. Wake For Law Rev 50:711-742

Williamson OE (1985) The economic institutions of capitalism. Free Press, New York 